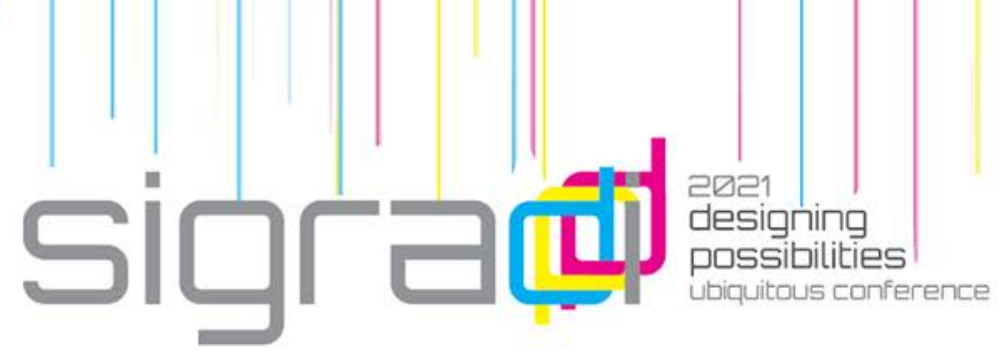

\title{
Emotion, Cognition, and The Practice of Teaching Architectural Design
}

\author{
Júlio César Alves Ferreira ${ }^{1}$, Claudio Lima Ferreira1 \\ ${ }^{1}$ UNICAMP, Brasil \\ docjulioferreira@gmail.com \\ limacf@unicamp.br
}

\begin{abstract}
From the view of concepts related to emotions and feelings treated in the field of cognitive - behavioral neuroscience and its relation with the teaching-learning processes, this paper searches to analyze educational strategies that can contribute to the field of emergency synchronous remote teaching architectural design. Methodologically, the bibliographical research of exploratory nature is related to an experience of investigation about pedagogical methods of teaching architectural design in a postgraduate course, developed, in the second semester of 2020, during the period of emergency synchronous remote teaching due to the SARS-Cov-2 coronavirus.We seek to comprehend the benefits and limits of remote emergency teaching practices of architectural design, looking at factors such as emotions and feelings as important mediation tools on teaching-learning processes.
\end{abstract}

Keywords: Architectural teaching, Emotions, Cognition in design, Teaching methods, Emergency remote teaching.

\section{Introdução}

A prática do projeto arquitetônico, assim como o seu ensino e crítica, envolve o acúmulo de informações, de experiências, ação criativa, formulação e verificação de ideais entre diversos outros fatores, não sendo decorrente exclusivamente da atuação planejada de seu projetista, mas também pelas influências mútuas dos participantes durante o processo, e em reflexões posteriores. Assim, ao tratarmos do processo de ensino do projeto, logo vem à tona a complexidade inerente ao ato de "conduzir" o desafio colocado pela folha em branco, seja qual o projeto em questão ou escala: na concepção de 
uma edificação, cadeira ou parque, o resultado não é definido num ato, mas se constrói por meio da evolução do processo criativo projetual, que por sua vez deriva de processo de aprendizagem.

Como podemos nos apropriar de ferramentas digitais que contribuam com o avanço das práticas de ensino e da análise de projeto arquitetônico em meio às transformações geradas durante o período de distanciamento social, decorrente de uma pandemia em escala mundial? A suspensão das aulas em modo presencial dos mais diversos cursos em todo o país causada pela proliferação do coronavírus SARS-Cov-2 a partir de março de 2020, e sua rápida reestruturação no formato de ensino remoto síncrono emergencial, estimulou a busca por ferramentas e abordagens que possam primeiramente amenizar os impactos de toda essa "cruel pedagogia do vírus" conforme a expressão do sociólogo português Boaventura de Souza Santos (2020).

Quando tratamos do projeto de arquitetura, lidamos, com uma atividade que engloba um processo complexo e de múltiplas habilidades cognitivas e motoras. Em seu artigo "O processo cognitivo e social do projeto" Fabrício e Melhado (2011) destacam que o processo mental de projeto se processa por meio de aprimoramentos sucessivos das ideias e da compreensão do problema e do objeto inicial. A partir de uma vasta revisão bibliográfica na temática de metodologias projetuais os autores caracterizaram as principais habilidades intelectuais exercidas durante o processo de projeto. São elas:

A capacidade de análise e síntese está presente na formulação do problema de projeto. Trata-se de obter, ordenar, classificar, e hierarquizar várias informações aparentemente desconexas e formular o problema a ser resolvido a partir de informações e demandas iniciais.

A criatividade e o raciocínio expressam a capacidade de propor soluções espaciais, técnicas, funcionais, financeiras, comerciais etc. originais, assim como desenvolver soluções coerentes para o problema proposto.

A representação e a comunicação implicam na forma de apresentar as soluções desenvolvidas - desenhos técnicos, maquetes, modelos virtuais- para serem executadas ou apreciadas. (Fabrício e Melhado, 2011, p.58)

A partir desses exemplos, surge um questionamento: onde se encontra o reconhecimento de fatores emocionais enquanto habilidades intelectuais para o desenvolvimento de processos de ensino-aprendizagem e análise projeto?

Tratando da formação de arquitetos e urbanistas, os cursos de graduação, em geral, tendem a ser organizados de maneira a fornecer várias disciplinas pontuais, finitas e pouco integradas entre si. Conforme Zein (2018) nos relata, as disciplinas tendem a ser agrupadas, de um lado, em "teóricas" e técnicas cuja incumbência é garantir aos estudantes o acesso a um elenco de 
informações, habitualmente genéricas sobre as diversas facetas do fazer arquitetônico - e de outro lado, em disciplinas "práticas", limitadas ao exercício projetual (ZEIN, 2018). É incumbida ao aluno a almejada síntese entre teoria, técnica e projeto, muitas vezes sintetizadas nas disciplinas de projeto.

Sendo todo o processo ensino e da análise de projeto arquitetônico uma atividade multidisciplinar que potencialmente articula distintas abordagens, visões e métodos sobre a prática projetual, torna-se também um espaço presencialmente ou de maneira remota - viável para experimentações metodológicas que atuem com ferramentas comuns a todos, como a expressão de emoções e sentimentos. Porém, conforme Lawson (2011) relata, a utilização do ateliê de projeto e de ferramentas de desenho tendem a ser os principais mecanismos para o desenvolvimento de seu processo.

Estando no presente momento, de distanciamento social dos ateliês presenciais, o ensino remoto síncrono emergencial de projeto de arquitetura se destaca como um tema de imensa importância. Conforme ressalta Lassance (2021), esse inédito momento de deslocamento forçado para o mundo virtual, pode nos apresentar algumas pistas para o enfrentamento dos desafios impostos as atividades da análise de projeto arquitetônico em contextos extremamente digitalizados, para o qual já caminhávamos.

Nesse sentido, a conciliação de conceitos sobre emoções e sentimentos advindos de estudos da neurociência tem muito a acrescentar ao cotidiano da prática educacional, aproximando todo um complexo conjunto de arranjos biológicos, estruturais, culturais, sociais e subjetivos que fazem parte da vida do ser humano em sua transversalidade.

\section{Ateliê de projeto remoto}

As recentes experiências com novas formas de ensino remoto a partir do contexto de excepcionalidade determinado pela pandemia SARS-Cov-2, se iniciou de forma mais evidente no Brasil em março de 2020. O chamado por alguns de um "novo normal", tem sido colocado à prova diariamente por milhões de estudantes e professores através de diversas ferramentas digitais das tecnologias da informação. A compreensão desse período será imprescindível para a realização das atividades mais determinantes de toda a vida social a partir daqui. Não poderia ser diferente no cotidiano do ensino de arquitetura e urbanismo.

Conforme Silva (2021) destaca, assistimos a uma "EADização" da docência, numa referência a expressão "Uberização", termo que trata das transformações sociais contemporâneas no mundo do trabalho. Assim, é necessário nos atentarmos a classificação desses novos sistemas, a fim de analisar suas formas de atuação e também suas consequências nos processos de ensino. 
Um ponto importante a ser destacado, é o do modelo de ensino praticado nesse momento de distanciamento social. O ensino remoto síncrono emergencial praticado nesse período, assemelha-se a modalidade EaD principalmente pela mediação da tecnologia no processo, em geral, mantêm os mesmos princípios da educação presencial. Vale ressaltar que atividades de ensino remoto estão sendo aplicadas pontualmente, como uma adaptação do ensino presencial auxiliado por tecnologias (salas de aula virtuais e alguma utilização de plataformas e aplicativos), sendo em sua maioria trabalhadas de maneira síncrona.

Em sua recente publicação "Ensinando na sala de aula online", Lemov(2021) destaca que nem todas as aulas remotas são iguais, mas em geral, a aprendizagem remota assume duas formas: Aprendizagem assíncrona e síncrona. Aprendizagem assíncrona acontece quando o trabalho de aprendizagem ocorre em diferentes momentos e em diferentes lugares. Exemplo: Quando os estudantes preenchem uma atividade que é publicada online e posteriormente enviado por email. Já a aprendizagem síncrona, é o tipo que acontece simultaneamente, mas em lugares diferentes. Qualquer tipo de aula que ocorre por plataformas digitais como Google Meet, Zoom, entre outras. (Lemov, 2021).

Ambos processos de aprendizagem têm limitações e benefícios. Neste artigo exploraremos o modelo remoto síncrono por ser a prática mais usual no presente momento em processos de ensino-aprendizagem em cursos de arquitetura e urbanismo no território brasileiro.

Ao observarmos o contexto brasileiro tendo como enfoque as Instituições de Ensino Superior (IES) privadas por exemplo, veremos que não houve praticamente uma parada para reformulações nos processos de ensinoaprendizagem no período inicial de isolamento social. Conforme Silva (2021) destaca, para garantir o pagamento das mensalidades, e também vislumbrar a "oportunidade" de testarem as suas ferramentas de EaD, foi praticamente imposto um grande movimento de digitalização das aulas, tudo isso ao custo de sacrifício de seus professores e sua nova demanda de trabalho, seja com a sua infraestrutura doméstica de espaço, internet, equipamentos, atualização de conteúdos didáticos, entre tantos outros fatores.

Cabe aqui salientar que estando em um período de adaptação a novos modelos de aprendizagem, como os de ensino remoto síncrono emergencial, já é possível destacar alguns dos benefícios e limitações mais evidentes. A aula síncrona pode replicar boa parte do clima escolar engajado semelhante a de uma sala de aula presencial. Professores podem fazer uma leitura da sala, realizando uma verificação da compreensão. Por outro lado, podem ocorrer "colisões" entre responsabilidades em "casa" e responsabilidades no "trabalho" 
devido a unificação desses espaços. Outros pontos importantes são a fadiga de tela e a capacidade de atenção em constante disputa (Lemov, 2021).

Fatos como esses ressaltam que quando tratamos de práticas pedagógicas no ensino remoto emergencial de arquitetura, observamos uma adaptação do modo tradicional de ensino para o modo remoto. Trata-se de uma questão para pensarmos. Quais as ferramentas ou abordagens que poderão nos auxiliar a melhorar os processos de ensino-aprendizagem em projeto de arquitetura?

Com os avanços neurocientíficos na área de medição e avaliação de resultados, nas últimas décadas, temos conhecido a organização e as funções do cérebro, das emoções, da atenção e das relações entre cognição, motivação e desempenho, construindo diálogos que contribuam com o cotidiano do educador conforme veremos a seguir.

\section{Neurociências, emoções e sentimentos em processos de ensino-aprendizagem}

A neurociência começa a esclarecer os complexos ingredientes neurais e comportamentais do que conhecemos como emoção, sentimentos, curiosidade, atenção, consciência, aprendizado, memória, além do sono e ritmos biológicos. Esse fato momentâneo, não nos impede de considerar que num futuro não muito distante um algoritmo de aprendizado de máquina será capaz de analisar dados biométricos de sensores em seu corpo, determinar o tipo de sua personalidade e suas variações de humor e calcular o impacto emocional que uma determinada canção ou local terá sobre você. (HARARI, 2018).

Assim, ocupando essa posição em um período em que o mundo reconhece os avanços da neurociência cognitiva, podemos utilizá-la para desenvolver, propor e aproximar seus componentes e princípios em processos de ensinoaprendizagem. Entre esses componentes da mente se encontram as emoções. Damásio (2012) nos apresenta as emoções e sentimentos como os sensores humanos para o encontro, entre natureza e circunstâncias por via do desenvolvimento individual e interações com o ambiente que nos ciscunda, seja ela digital, ou não. Esses elementos servem de guias internos e ajudamnos a comunicar com os mais diversos canais da percepção.

Em sua obra "O erro de Descartes" (2012) Damásio argumenta por diferentes caminhos como a rotineira divisão cartesiana entre razão e emoção domina tanto os olhares sobre nossa sociedade. Conforme a compreensão dos processos da emoção e dos sentimentos se expande e começa a integrar outras áreas do conhecimento, podemos traçar aproximações com a prática 
do ensino em paralelo à regulação biológica, com seus controles homeostáticos, impulsos e instintos. Nessa direção, Mora destaca:

Conhecer que as mudanças sinápticas do cérebro são resultadas do ensino que recebem seus alunos pode transformar a atitude de muitos professores e produzir neles um tom diferente, mais emocional e cognitivo, possivelmente impactando na forma em que ele vê o ensino. (MORA, 2017, p. 32)

Vale destacar que para esse breve artigo, nos atemos a visão de "emoção" e "sentimentos" expostas por Mora (2017) e Damásio (2012). Aspectos que ambos os autores ressaltam que não são definições ortodoxas, mas propostas para auxiliar na compreensão e avanço de futuras investigações desses fenômenos.

Damásio (2012) ressalta também, que a essência da emoção está na coleção de mudanças no estado do corpo, induzidas numa infinidade de órgãos, por meio das terminações das células nervosas e sob o controle de um sistema cerebral dedicado. Este, por sua vez, responde ao conteúdo dos pensamentos relativos a uma determinada entidade ou acontecimento. Muitas das alterações do estado corporal como alteração na cor da pele, postura e expressão facial são efetivamente perceptíveis para o observador externo.

Sendo as emoções a combinação de um processo avaliatório mental, simples ou complexo, com respostas dispositivas a esse processo, em sua maioria dirigidas ao corpo propriamente dito, resultando num estado emocional do corpo, mas também dirigidas ao próprio cérebro, resultando em alterações mentais adicionais. A percepção individual de todas essas mudanças seriam os sentimentos. (DAMÁSIO, 2012, p.128)

Conforme ocorrem as alterações no corpo ou na mente, o indivíduo tem reflexos de sua existência e pode acompanhar a evolução desses processos, como notar as mudanças no estado corporal e seu desenrolar durante segundos ou minutos. Esse processo de acompanhamento contínuo, essa experiência do que o corpo está fazendo enquanto pensamentos sobre conteúdo específicos continuam a desenrolar-se, é a essência daquilo que o autor chama de sentimento.

Os sentimentos seriam por sua vez, os processos que nos levam a conhecer as emoções, através do medo, atenção, prazer, frustração entre tantos outros(MORA, 2017). O autor também relaciona o tema ao tratar de questões de ensino-aprendizagem, destacando fatores de conexão por meio da emoção e da empatia. As emoções são então postas como a base mais importante na qual todos os processos de aprendizado e memória são baseados. (MORA, 2017, tradução dos autores). 
Dessa forma, práticas que atuem explorando fatores de emoção e sentimentos em seu processo de ensino-aprendizagem, tem muito a contribuir para atividades de ensino remoto síncrono emergencial. Nesse sentido, foi desenvolvida uma revisão conceitual de emoções e sentimentos específicos, a partir de princípios da neurociência em uma experiência de ateliê de projeto remoto, conforme veremos a seguir.

\section{Metodologia: Emoções e Sentimentos em processos de análise de projeto arquitetônico remoto síncrono emergencial}

A experiência apresentada a seguir foi desenvolvida durante o curso da disciplina de pós-graduação "Ambiente construído e comportamento humano", coordenada pela Profa. A Dra. Doris Catharine C. K. Kowaltowski -UNICAMPdurante o segundo semestre de 2020. As etapas detalhadas abaixo, foram desenvolvidas em dois encontros específicas no decorrer do curso da disciplina e posteriormente analisadas.

A atividade desenvolvida na disciplina, teve como intuito, discutir metodologias de pesquisa do ambiente construído a partir das especificidades do contexto pandêmico. Como passo inicial, os discentes deveriam escolher uma linha temática específica a partir de temas pré-definidos e então desenvolver dinâmicas interativas, remotas síncronas de forma que apresentassem as metodologias de pesquisa usuais para os temas selecionados e suas adaptações ao contexto de distanciamento social devido ao coronavírus SARS-Cov-2.

A temática adotada para o desenvolvimento da atividade foi a de avaliação de espaços habitacionais, tendo ênfase em melhorias do ambiente construído durante o período pandêmico SARS-COV-2. Para a realização das atividades, foram realizados levantamentos em base de dados -SCOPUS- por meio dos seguintes termos: "Built environment" And "Housing Project" And "Covid 19".

Em decorrência do tempo destinado para as dinâmicas junto a turma, foi realizado uma seleção de um número mínimo de materiais para que pudessem ser amplamente explorados em contato com a turma conforme veremos a seguir. Um dos pontos para a atividade foi sobre a interação com os colegas discentes de maneira dinâmica e interativa em encontros remotos, a fim de que pudéssemos observar sua compreensão do conteúdo, métodos e processos do projeto em um experiência síncrona. Esse conjunto de interações segue aqui analisada por dois princípios da neurociência.

\subsection{Curiosidade}


Dentre os diversos sentimentos "exploráveis" dentro de um processo de ensino-aprendizagem, o fator curiosidade possui grande relevância. Sendo a curiosidade essa "característica inata do mamífero que o leva a explorar e que é muito dependente do estado nutricional, ritmos circadianos, hora de luz ao dia e de diferentes outros estímulos e situações". O despertar da curiosidade tem o potencial de romper a monotonia e trazer à luz fatos e visões até então ignoradas pelos estudantes. "Sem curiosidade não há atenção nem conhecimento" (MORA, 2017. Tradução dos autores).

Cabe então ao professor, ou ao mediador da atividade, a função de conduzir esse processo de maneira que propicie a seus alunos condições para compreender seu aprendizado de maneira curiosa, ao ponto que os mesmos possam alcançar conhecimentos não previstos em um primeiro momento, ainda mais quando tratamos de dinâmicas remotas onde o estudante tem acesso às mais diversas informações via internet.

Se deduz que a curiosidade que se satisfaz por meio do aprendizado tem como base cerebral o prazer, o que, em sua vez, reforça a ideia de que a busca de conhecimento e a tomada de decisão conducentes a obter esse conhecimento é biologicamente agradável. Prazer que não é simples prazer 'mental', mas compartilha os mesmos circuitos e substratos neurais que os prazeres biológicos (MORA, 2017, p. 78, tradução dos autores).

Assim, o educador tem a função de propor atividades que os alunos tenham condições de realizar e que despertem a curiosidade que os motivará em seu processo, e os manterá conectados a atividade e não somente a sua ferramenta de acesso ao conteúdo.

\subsection{Atenção}

O segundo sentimento selecionado está relacionado à capacidade de captar e reter a atenção dos alunos. Sem atenção não há aprendizado. (MORA, 2017, p. 86, tradução dos autores). Sendo um dos grandes desafios constantes da prática de ensino, a retenção da atenção deve ser constantemente trabalhada e planejanda, pois conforme Mora destaca:

Hoje a neurociência nos ensina que a atenção não é, como até há pouco se pensava, um mecanismo cerebral singular único, mas que há atenções diferentes, com processos cerebrais diferentes. Há uma atenção base, aquela que quando estamos acordados, conscientes, nos permite estarmos alertas ou vigilantes, mas sem foco preciso; outra de foco fixo, absorvente; outra orientativa, também outra que é executiva, e por último se fala de uma atenção inconsciente virtual, global (MORA, 2017, p. 87, tradução dos autores). 


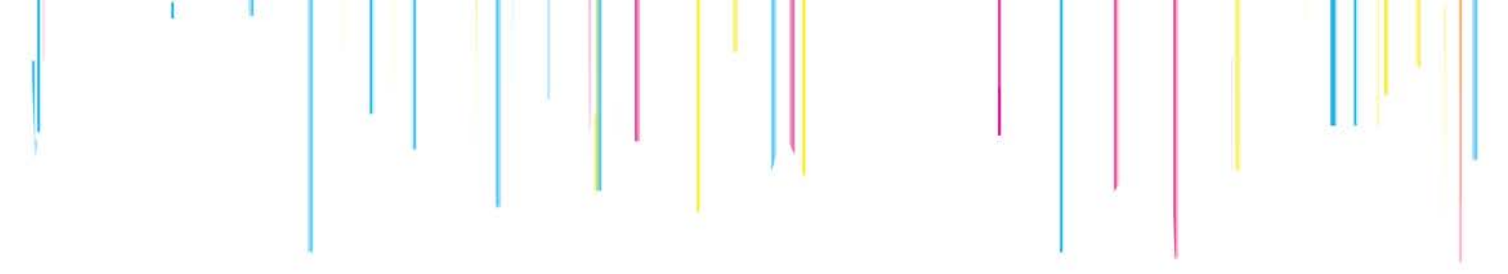

O uso da alteração facial, voz e humor são alguns dos recursos mais usuais para a manutenção da atenção por partirem de um ferramental comum, o próprio corpo humano. Cosenza e Guerra (2011) destacam que a natureza nos dotou de mecanismos que permitem selecionar a informação que é importante em determinado período. Assim, para criar ou explorar um determinado envolvimento em sala de aula, alguns recursos como alteração facial, voz e humor contribuem para a manutenção do humor. É necessário ressaltar que práticas remotas, esse recurso pode ser muito prejudicado, seja pela focalização de expressões através de telas, ou em contextos de câmeras e microfones "fechados".

Educadores devem se atentar a habilidades e estratégias diferentes para trabalhar a atenção de seus alunos, compreendendo que o cérebro humano não tem a capacidade de processar todas as informações que chegam a ele, havendo a necessidade da atribuição de significância para o reforço da atenção.

É necessário esclarecer que a compressão desses princípios se faz importante para uma leitura mais completa sobre a complexidade da análise da fisiologia humana e do desafio transdisciplinar dos diálogos entre os campos de pesquisa. Conforme destacado por Cosenza e Guerra (2011) a contribuição da neurociência para a educação não se encontra em propor uma nova pedagogia, mas sim na possibilidade de colaborar para fundamentar práticas pedagógicas já realizadas, verificando sua eficácia através do funcionamento cerebral. Com esses fatores e ressalvas estabelecidos, passeamos então para as etapas de apresentação e suas análises.

\section{Dinâmicas e resultados}

\subsection{Etapa 01}

Conforme citado, a primeira dinâmica foi desenvolvida com o intuito de contextualizar metodologias de pesquisas em psicologia ambiental que fossem usualmente utilizadas na avaliação de espaços habitacionais. Foram apresentadas de maneiras expositivas e síncronas por meio de plataforma de videoconferência - Google Meet. Conceitos como de Metodologia Ergonômica para o Ambiente Construído (MEAC), Avaliação Pós Ocupação (APO), e a de Atributos Induzidos ou Constelação de atributos.

Posteriormente a apresentação expositiva das metodologias, foi proposto para a turma uma rápida atividade individual onde por meio da plataforma digital Mentimeter. A turma deveria responder a seguinte pergunta: "Quais palavras lhe vêm à mente ao pensar no projeto de unidades habitacionais a partir das experiências vividas durante a pandemia COVID-19?" 


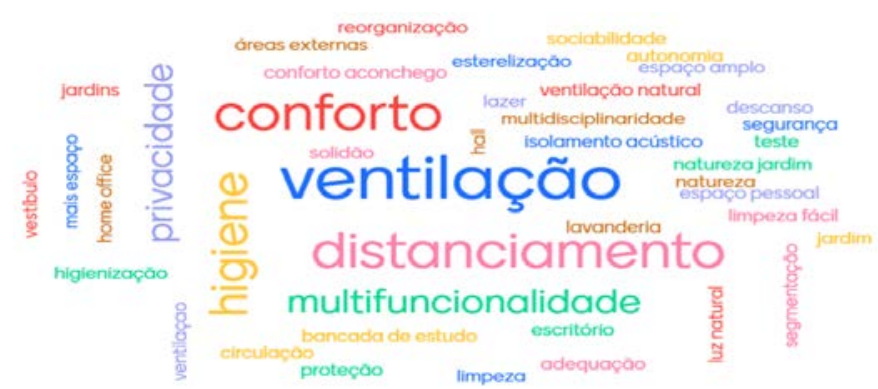

Figura 1. Nuvem de palavras - plataforma: Mentimeter Fonte: Autores

Essa primeira etapa da atividade teve como intuito provocar uma reflexão sobre a relação entre soluções projetuais em meio ao nosso período/situação específica ao mesmo tempo de gerar um debate sobre o conhecimento comum da turma, destacado através do nuvem de palavras interativas gerado pela plataforma. Essa etapa teria o papel de conectar o conhecimento dos alunos à próxima etapa da dinâmica, ressaltando a curiosidade dos participantes através das diferentes visões iniciais sobre o mesmo tema e que logo seriam amarradas em atividade interativa logo a seguir.

Nesse segundo momento, partimos para apresentação expositiva de estratégias, adaptações e avaliação dos espaços de Habitação. Essa etapa da atividade foi estruturada a partir da síntese dos artigos "COVID-19 and Living space challenge. Well-being and Public Health recommendations for a healthy, safe, and sustainable housing" e "COVID-19 Lockdown: Housing Built Environment's Efects on Mental Health". Após esse momento, passamos os trabalhos para a plataforma online Miro para que os grupos pré-estabelecidos pudessem refletir e materializar suas visões do tema a partir da seguinte base:

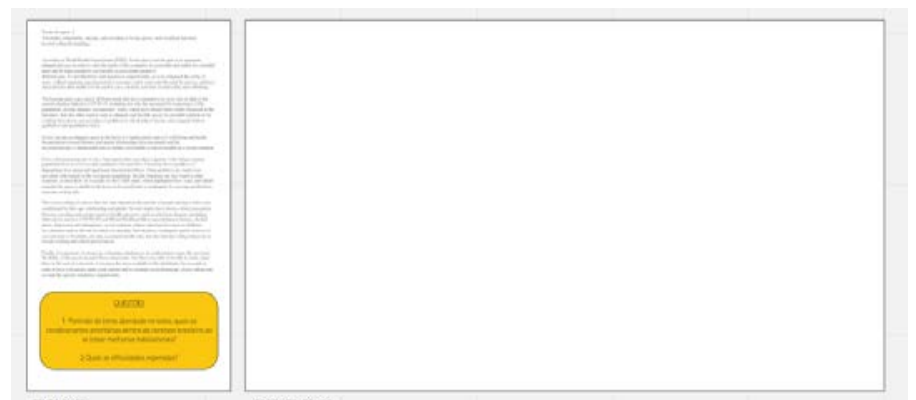

Figura 02. Exemplo de Ârea virtual para produção de etapa -Plataforma: Miro Fonte: Autores 
Por questões de organização e aprofundamento temático para o momento das dinâmicas, foram selecionados quatro conceitos apresentados na bibliografia citada. Cada grupo recebeu um espaço virtual dentro da plataforma digital Miro onde encontrariam trechos do artigo como base para a atividade seguinte e mais as seguintes perguntas a serem respondidas: Partindo do tema abordado no texto, quais as condicionantes prioritárias dentro do contexto brasileiro ao se tratar melhorias habitacionais? Quais as dificuldades esperadas?

As questões apresentadas poderiam ser respondidas por textos, imagens, representações gráficas, entre outras ferramentas de expressão gráfica que o grupo adotasse dentro do seu tempo de produção de 25 minutos. Após esse período de produção, cada grupo deveria apresentar de maneira sintetizada sua visão sobre a situação em questão e suas propostas projetuais.

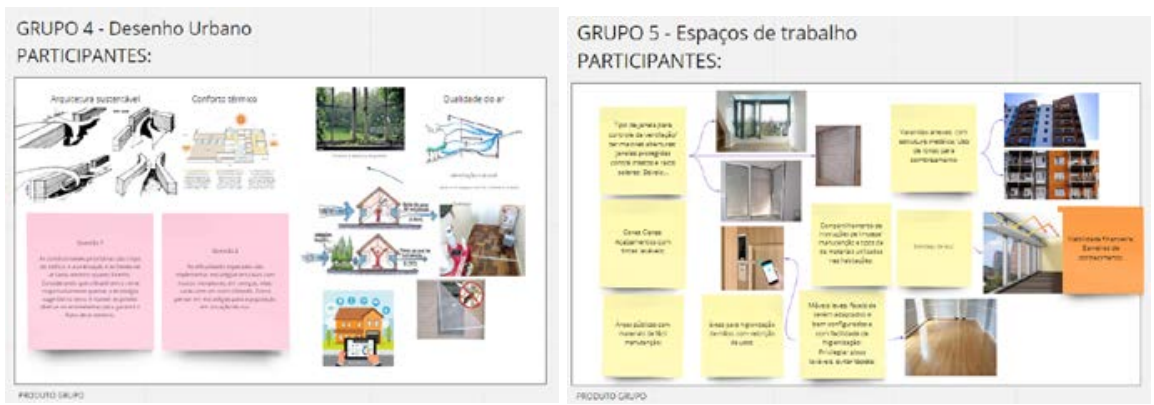

Figura 03. Exemplos de produção em área virtual-Plataforma: Miro. Fonte: Autores

Os resultados destacaram com clareza os contextos temáticos específicos propostos, porém na abordagem de dois grupos não ficou explícito o contexto de melhorias habitacionais conforme proposto na atividade. As apresentações destacaram conceitos e ferramentas de projetos mais aplicáveis em etapas iniciais de projeto do que no sentido de melhorias, demonstrando-se desatentos com a atividade e suas propostas. Essa descontextualização com a proposta somada a não existência de um eixo comum de problema a ser solucionado pelos grupos, foram fatores que nos parecem carecer de revisão para a formulação da etapa 02. 


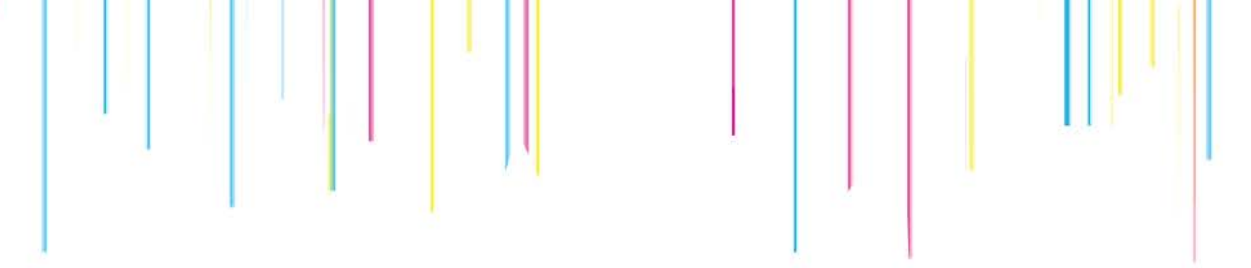

\subsection{Etapa 02}

Conforme citado, a segunda etapa foi desenvolvida em um novo encontro e de maneira a aproveitar a experiência da anterior, focando em decisões projetuais com base científica. Assim determinados pontos do artigo apresentado na primeira fase, foram retomados e melhor exemplificados com uma breve apresentação expositiva pré-dinâmica via Google Meet.

Assim, na etapa 02, os grupos deveriam então desenvolver e apresentar soluções projetuais que evitem a propagação do Covid-19 em ambientes habitacionais a partir de 4 conceitos específicos apresentados no artigo "COVID-19 and Living space challenge. Well-being and Public Health recommendations for a healthy, safe, and sustainable housing" Ao invés de uma pergunta temática para cada equipe como na primeira dinâmica, agora os grupos deveriam atuar todos sobre a mesma base, uma planta de reconstituição de um apartamento padrão de $55 \mathrm{~m}^{2}$.

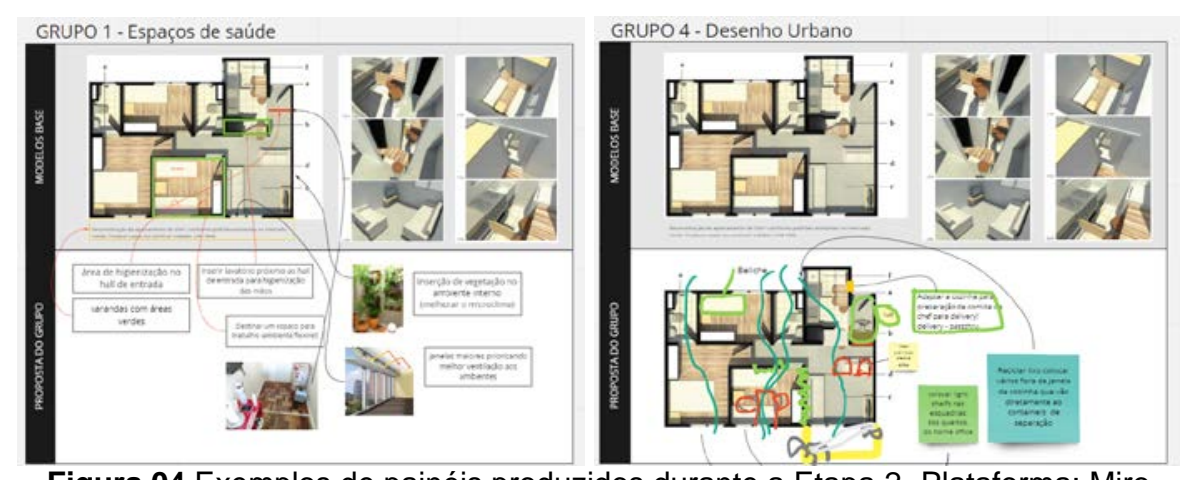

Figura 04 Exemplos de painéis produzidos durante a Etapa 2 -Plataforma: Miro Fonte: Autores

Revisando a atividade podemos notar que apesar da dinâmica ter sido realizada de maneira muito sintetizada devido ao escasso tempo reservado, os resultados obtidos nessa etapa foram satisfatórios e mais alinhados à proposta da atividade do que os resultados da apresentados na etapa 1. Os grupos se apropriaram do material base de maneiras distintas, porém atendendo a demanda de adequações possíveis em melhorias habitacionais, inclusive retomando espontaneamente soluções e referências projetuais previamente 
apresentadas, demonstrando sua atenção com o processo de atividade. Em diversos momentos da atividade os grupos demonstraram seu engajamento, seja com o debate sobre o tema, ou com as funcionalidades das plataformas, que para muitos, ainda era uma novidade.

Exemplos como esse são importantes para que pesquisadores possam repensar sua prática, possam aprimorar seu repertório de ferramentas e abordagens, ainda mais, durante o contexto pandêmico, ressaltando primeiramente a busca por trabalhos que avaliam questões do comportamento humano e suas relações com o ambiente construído. Outro fator importante, é que desse processo, podemos tirar algumas conclusões sobre a presente prática de ensino remoto de projeto arquitetônico. Vale a pena ressaltar que a atividade foi desenvolvida em um contexto de disciplina de pós-graduação, em que os alunos apresentam maior maturidade em relação a turmas de graduação.

\section{Considerações finais}

O presente artigo aproximou áreas como a neurociência cognitiva comportamental, por meio de olhares sobre emoções e sentimentos com o processo de ensino remoto síncrono emergencial de projeto arquitetônico ocorrido em decorrência da proliferação do coronavírus SARS-Cov-2.

Ao longo do artigo, foram abordadas questões sobre a formação do arquiteto urbanista brasileiro, de toda a cultura de ateliê de projeto e sua estrutura presencial que se permanece rígida, mesmo em um período de aceleradas transformações impostas pelo ensino remoto emergiencial.

É preciso salientar que conforme apresentado, o campo de estudos da neurociência tem muito a contribuir em novos processos de ensino remoto, agregando fatores biológicos, comportamentais e sensoriais à prática de processos de ensino-aprendizagem. Em um período onde nos encontramos conectados por longos periodos de tempo aos meios de tecnologia da informação, o conhecimento de toda esfera biológica e íntima de estudantes e professores se destaca ao promover uma conexão mais "consciente" com as ferramentas digitais. 
Cabe novamente destacar que as neurociências estudam princípios que descrevem a estrutura e o funcionamento neurais, buscando a compreensão dos fenômenos observados. A educação tem outra natureza e finalidades, como a criação de condições para o desenvolvimento de competências. E não é estruturada apenas por caracaterísticas biológicas, mas também por divertos outros aspectos como as dinâmicas da sala de aula e do contidiano doméstico dos discentes e docentes.

Como considerações específicas sobre os resultados em cada etapa de análise apresentada na metodologia verifica-se que: Etapa 1 as apresentações destacaram conceitos e ferramentas de projetos mais aplicáveis em etapas iniciais de projeto do que no sentido de melhorias, demonstrando-se desatentos com a atividade e suas propostas. Essa descontextualização com a proposta somada a não existência de um eixo comum de problema a ser solucionado pelos grupos, foram fatores que afetaram diretamente a curiosidade e atenção dos alunos.

Etapa 2 -Os grupos se apropriaram do material base de maneiras distintas, porém atendendo a demanda de adequações possíveis em melhorias habitacionais, inclusive retomando espontaneamente soluções e referências projetuais apresentadas durante a dinâmica que constavam dentro do painel do miro previamente apresentado, demonstrando sua atenção com o processo de atividade. Em diversos momentos da atividade os grupos demonstraram seu engajamento, seja com o debate sobre o tema, ou com as funcionalidades das plataformas, que para muitos, ainda era uma novidade.

Em uma consideração geral, pode-se verificar que a análise da experiência de revisão e crítica de projeto arquitêtonico no formato de ensino remoto síncrono emergencial aqui relatada, destaca benefícios e limites encontrados no processo no presente momento. Entre os aspectos positivos, fica claro que esse sistema pode construir e manter conexões sociais. É um sistema que permite maior compartilhamento entre trabalhos produzidos, processos de atividades dos estudantes e também a verificação de compreensão em tempo real. 
Lassance, G. Consequências não-digitais do meio digital para o ensino de projeto. V!RUS, São Carlos, n. 21, article number 6,DOI 10.4237/virus journal

Lawson, B., \& Medina, M. B. (2011). Como arquitetos e designers pensam (1 ${ }^{\mathrm{a}}$ edição). Editora Oficina de Textos.

Lemov, D., Champion, T. L. a C., Daros, T., \& Rosa, S. M. M. da. (2021). Ensinando na Sala de Aula On-line: Sobrevivendo e Sendo Eficaz no Novo Normal (1 $1^{\mathrm{a}}$ edição). Penso.

Mora, F. (2017). Neuroeducación / Neuroeducation: Solo se puede aprender aquello que se ama / You can only learn what you love (Edição: edición). Alianza Editorial $\mathrm{Sa}$.

Mora, F. (2004). Continuum: Como Funciona o Cérebro? Artmed Editora.

Pallasmaa, J. (2018). Essências (Edição: 1). Editora Gustavo Gili.

Royal Institute of British Architects, RIBA. (2021) RIBA publishes results of COVID-19 student survey. www.architecture.com

Santos, B. de S. (2020). A cruel pedagogia do vírus. Boitempo Editorial.

Silva, H. de A. (2021). Reflexões políticos-econômicas o o atelier de projeto de arquitetura em tempos de pandemia do covid-19. Revista Projetar - Projeto e Percepção do Ambiente, 6, (pp. 168-173). https://doi.org/10.21680/2448296X.2021v6n1ID22910 